\section{A área de Política Linguística nas licenciaturas em Letras no Brasil}

The area of Language Policy in graduation in Letters in Brazil

Lília dos Anjos AFONSO (UFPB) liliadosanjos@gmail.com

Socorro Cláudia Tavares de SOUSA (UFPB) sclaudiats@gmail.com

Recebido em: 24 de jan. de 2019. Aceito em: 12 de jun. de 2019.
AFONSO, Lília dos Anjos; SOUSA,

Socorro Cláudia Tavares de. A área de Política Linguística nas licenciaturas em Letras no Brasil. Entrepalavras, Fortaleza, v. 9, n. 3, p. 382-402, setdez/2019.

Resumo: Este trabalho tem como objetivo investigar o espaço da Política e Planejamento Linguístico nos currículos das licenciaturas em Letras no Brasil. Para atingirmos tal objetivo, realizamos uma análise textual em 41 ementas provenientes de 34 Projetos PolíticoPedagógicos. Identificamos a presença de 13 disciplinas de Política Linguística, bem como conteúdos relacionados à área em 27 outros componentes curriculares. Categorizamos alguns tópicos recorrentes que são: políticas linguísticas para uma língua ou um contexto específico, políticas de ensino de línguas, políticas linguísticas e suas implicações etc.. Os resultados indicam que o conhecimento da dimensão política da língua é uma competência necessária na formação de professores, provendo o futuro docente de uma perspectiva mais ampla de língua, o que pode torná-lo mais preparado para lidar com os diferentes desafios de ser professor em um mundo globalizado, em contexto de falantes de línguas minorizadas, em contextos sociolinguísticos complexos como as regiões de fronteiras, dentre outros.

Palavras-chave: Políticas Linguísticas. Formação de Professores. Ensino de Línguas. 
Abstract: This article aims to investigate how the field of Language Policy and Planning is present in the curricula from teaching degrees in Languages Courses in Brazilian Universities. To achieve this goal, we analyzed 41 syllabus from 34 PoliticalPedagogical Projects. We identified 13 disciplines of Language Policy, as well as content related to the area in 27 other curricular components. We categorized some recurrent topics such as: language policies for a specific language or context, language teaching policies, language policies and their implications, among others. The results indicate that knowledge of the political dimension of language is a necessary competence in teachers' training, providing the future teacher a broader perspective of language, which can give the opportunity to get them more prepared to deal with the different challenges of being a teacher in a globalized world, in the context of speakers of minority languages, in complex sociolinguistic contexts such as border regions, among others.

Keywords: Language Policies. Teacher Training. Language Teaching.

\section{Introdução}

Este trabalho tem como objetivo investigar o espaço da área de Política e Planejamento Linguístico (doravante PPL) nos currículos das licenciaturas em Letras no Brasil. Para atingirmos tal objetivo, realizamos uma análise textual em 41 ementas provenientes de 34 Projetos Político Pedagógicos desses cursos. Nesse sentido, pretendemos responder à seguinte pergunta de pesquisa: o campo de PPL está presente no currículo dos cursos de licenciatura de Letras dos institutos federais e das universidades públicas no Brasil e, se estiver, como se caracteriza essa presença?

Investigações sobre a relação entre a área de PPL e a formação de professores é um tema que tem gerado interesse de pesquisadores, tanto no cenário internacional quanto no nacional. Sem a pretensão de sermos exaustivas, é possível citar o trabalho de Throop (2007, p. 47) que defende a tese de que "[...] a preparação de professores deve ser expandida para incluir a dimensão da política e do planejamento linguístico" ${ }^{1}$, em pesquisa realizada no contexto de ensino de aprendizes que não têm o inglês como L1 (English Language Learner - ELL) e de educação bilíngue (Bilingual Education - BLE); e o de Arias e Wiley (2013, p. 83) que também defende a tese de que a "Linguística Aplicada, com o seu subdomínio da política e do planejamento linguístico pode contribuir significativamente para o ensino de línguas" ${ }^{2}$, no contexto

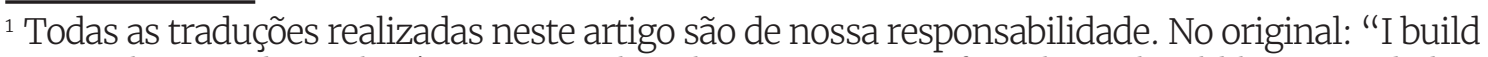
on Varghese and Stritikus' argument that the preparation of teachers should be expanded to include the dimension of language planning and policy. " (THROOP, 2007, p. 47).

${ }^{2}$ No original: "Applied linguistics, with its sub-domains of language planning and policy can make significant contribuitions to language teaching. " (ARIAS; WILEY, 2013, p. 83). 
v. 9 (3)

$382-402$

set-dez

2019

de preparação de professores para o ensino de aprendizes de língua inglesa no Arizona/Estados Unidos³.

No Brasil, destacamos o trabalho de Fraga (2014, p. 45) que também defende "[...] a tese da importância de a formação (inicial e continuada) do licenciado em Letras contemplar questões afetas às Políticas Linguísticas [...]". A autora fez um levantamento inicial sobre a presença da área de PPL em cursos de Pós-Graduação da área de Letras e Linguística, bem como na área da Educação, Antropologia e Ciências Sociais e verificou que a Política Linguística, quando aparece, é como conteúdo em diferentes disciplinas.

Enfocando os cursos de graduação em Letras, Afonso (2017) investigou o espaço do campo no currículo dos cursos de licenciatura - nas ementas das disciplinas e no perfil dos egressos. Este artigo se configura como um recorte dos resultados obtidos neste trabalho que, por sua vez, está inserida em um Projeto de Pesquisa intitulado "Política Linguística no Brasil: as práticas de pesquisa, as práticas de ensino e a agência dos professores" $"$.

Para fins de organização retórica, dividimos este trabalho em quatro partes, afora esta introdução: na primeira, apresentamos um percurso cronológico resumido de algumas noções de política linguística (HAUGEN, 1959; COOPER, 1989; SCHIFFMAN, 1996, 2006; SPOLSKY, 2004, 2009, 2012; JOHNSON, 2013); na segunda, descrevemos o percurso metodológico adotado para a realização desta pesquisa; na terceira, descrevemos e discutimos os resultados obtidos a partir da análise das ementas provenientes de disciplinas de Política Linguística e de outros componentes curriculares que apresentaram conteúdo da área de PPL; e na quarta, apresentamos as considerações finais as quais chegamos após a análise e discussão dos dados.

\section{Concepções de Política Linguística}

A terminologia Política Linguística representa, sobretudo, uma concepção histórica e epistemológica de conceber seu objeto de estudo, dado que os estudos iniciais realizados nesta área adotavam a expressão

\footnotetext{
3 Em 2000, o Estado do Arizona aprovou a Proposição 203 que restringiu a educação bilíngue. Essa legislação é também conhecida por English for the Children e advoga a ideia de que a proficiência em língua inglesa é condição necessária para os filhos de imigrantes terem melhores oportunidades no país, daí o Estado tem a obrigação de prover este ensino desde a mais tenra idade.

4 Projeto financiado pelo Conselho Nacional de Desenvolvimento Científico e Tecnológico (CNPQ) com vigência no período de 2015 a 2017 (Processo n 454034/2014-8).
} 
Planejamento Linguístico e outras como Glotopolítica, Aménagement Linguistique com abordagens nem sempre convergentes (CALVET, 2007). Ao longo do tempo, ambos os termos - Política Linguística e Planejamento Linguístico - coexistiram e, mais recentemente, o uso do termo Política Linguística passou a ser o mais utilizado. De acordo com Silva (2013), a falta de um consenso a respeito de uma terminologia ocorre pelo fato de que o campo de investigação da PPL é relativamente recente, gerando, por conseguinte, alterações na forma de conceber a política linguística.

O termo Planejamento Linguístico surgiu no final dos anos 1950, a partir de um estudo de Haugen (1959) que investigou a situação da língua norueguesa no período de independência da Noruega. Para o autor, o planejamento linguístico estava relacionado à "[...] atividade de preparação de uma ortografia normativa, gramática e dicionário para a orientação de escritores e falantes em uma comunidade de fala não-homogênea" ${ }_{5}$ (HAUGEN, 1959, p.08). Nesta perspectiva, os conhecimentos linguísticos eram aplicados à elaboração de instrumentos linguísticos. As decisões em torno das línguas eram provenientes da esfera governamental e, portanto, de natureza top down (de cima para baixo).

Nos anos 1980, os estudos de Cooper (1989) revelaram uma concepção de Planejamento Linguístico distinta da perspectiva restrita apenas às decisões governamentais. Este autor considerava que tal visão do planejamento, nos anos 1960, não levava em consideração as mudanças sociais. Em contraposição a essa perspectiva, Cooper (1989) entendia o planejamento linguístico como algo complexo, relacionado às transformações sociais e políticas. Neste sentido, ampliou a noção, apresentando-a como "[...] esforços deliberados para influenciar o comportamento dos outros na forma como a língua é adquirida, estruturada ou alocada, não restringindo os planejadores, nem o público-alvo, nem especificando uma forma ideal de planejamento"6 (COOPER, 1989, p. 45). Deste modo, Cooper constrói a sua noção de Planejamento Linguístico a partir do seguinte questionamento: "Quem

\footnotetext{
5 No original: "By a language planning I understand the activity of preparing a normative orthography, grammar, and dictionary for the guidance of writers and speakers in a non-homogeneous speech community" (HAUGEN, 1959, p. 08).

${ }^{6}$ No original: "[...] deliberate efforts to influence the behavior of others with respect to the acquisition, structure, or functional allocation of their language codes. This definition neither restricts the planners to authoritative agencies, nor restricts the type of the target group, nor specifies an ideal form of planning" (COOPER, 1989, p. 45).
} 
v. 9 (3)

$382-402$

set-dez 2019 planeja, o que planeja, para quem planeja e como planeja?"7 (COOPER, 1989, p.31) (Grifos nossos). Resumidamente, apresentamos essas respostas na figura 1.

Figura 1 - Concepção de Planejamento Linguístico em Cooper.
- Qualquer um pode realizar planejamento linguístico como indivíduos, organizaçōes sociais, instituiçōes governamentais...

planeja?

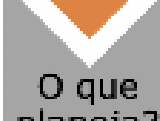

- O planejamento linguístico pode incidir sobre decisões relacionadas ao "corpo" da língua (corpus), às funções das línguas (status) e à ampliação do número de usuários (aquisição).

- Os destinatários são denominados como "outros", podendo ser uma naçăo, uma comunidade, um indivíduo...

quem

planeja?

- Não existe um planejamento ideal. Tal planejamento é realizado, considerando as mudanças sociais e políticas em cada contexto em que os indivíduos estão inseridos.
Como

planeja?

Fonte: Elaboração própria a partir de Cooper (1989).

Nos anos 1990, a obra de Schiffman (1996) - Language Policy and Linguistic Culture - amplia o que pode ser considerado Política Linguística. Para o autor, existe uma ligação entre Política Linguística e Cultura Linguística, dado que "[...] a política linguística está em última análise, fundamentada na cultura linguística [...]"8 (SCHIFFMAN, 1996, p. 05). Esta, por sua vez, abrange o conjunto de mitos, estereótipos, crenças, atitudes sobre as línguas e suas variedades. Para Schiffman (1996), política linguística é uma construção social que envolve tanto aspectos de natureza explícita (legais, administrativos...) quanto aspectos de natureza implícita ('bagagem' cultural dos falantes em relação à língua e suas variedades). De acordo com o autor, essa bagagem cultural não pode ser deixada de fora de uma política linguística.

Essa perspectiva relaciona aspectos à política linguística que não eram considerados em estudos realizados anteriormente (SOUSA; ROCA, 2015). A percepção de Schiffman (1996) expande a concepção

\footnotetext{
7 No original: "Who plans what for whom an how?"

${ }^{8}$ No original: "[...] language policy is ultimately grounded in linguistic culture [...] (SHIFFMAN, 1996, p.05).
} 
de política linguística por evidenciar que as políticas não são apenas aquelas formais, explícitas, declaradas, podendo ser também políticas informais, implícitas e ocultas - nem sempre tão evidentes para o público. O autor ilustra com o exemplo do inglês que, apesar de não estar formalmente explícito como língua oficial na Constituição dos Estados Unidos, constitui-se como língua dominante e exclui outras línguas, o que é possível perceber, por exemplo, a partir dos diversificados programas de ensino de línguas nos Estados americanos, que privilegiam o inglês, como é o caso do movimento English Only ${ }^{9}$.

Na década de 2000, a proposição teórica de Spolsky (2004, 2009, 2012) expande ainda mais a noção de política linguística. Isso porque a configuração estabelecida por Spolsky propõe uma independência da relação entre política linguística e cultura linguística. Neste sentido, política linguística é uma construção teórica que "explica as escolhas feitas pelos falantes com base em padrões definidos por regras reconhecidas por uma comunidade (ou comunidades) de fala das quais são membros" ${ }^{10}$ (SPOLSKY, 2009, p. 01).

Partindo de tal percepção, a noção de Política Linguística do autor é construída a partir de uma visão multidimensional, ou seja, constituída de diferentes dimensões que são independentes, mas estão inter-relacionadas que são as práticas, as crenças e a gestão da língua. As práticas são as escolhas da língua que os membros de uma dada comunidade de fala realizam em seu dia a dia, tais como: de uma variedade específica para realizar uma determinada função comunicativa, de uma variante linguística de acordo com o interlocutor, de que variedade usar para mostrar ou esconder uma identidade, dentre outras. Spolsky (2012) ainda informa que essas práticas representam a política linguística real de uma comunidade de fala. Um exemplo é uma ferramenta criada para o navegador Google Chrome que substitui o termo "refugiados" por "seres humanos" em matérias que façam menção a esse grupo de pessoas. O objetivo dessa prática linguística é gerar empatia em relação a esses imigrantes ${ }^{11}$.

9 O Movimento English Only tem como objetivo instituir o inglês como língua oficial nos Estados Unidos através de uma emenda constitucional. Esse movimento teve bastante repercussão na medida em que alguns Estados o declararam como língua oficial como é o caso de Luisiana, Massachusetts, Carolina do Norte, Colorado, dentre outros.

${ }^{10}$ No original: "account for the choices by individual speakers on the basis of rulegoverned patterns recognized by the speech community (or communities) of which they are members". (SPOLSKY, 2009, p.01).

${ }^{11}$ Disponível em: <http://thegreenestpost.com/a-ferramenta-que-quando-instaladano-computador-troca-o-termo-refugiados-por-seres-humanos-em-todas-as- 
v. 9 (3)

$382-402$

set-dez

2019

A segunda dimensão está relacionada às crenças sobre a língua e representam os valores atribuídos às variedades e às variantes linguísticas e ainda as crenças dos membros de uma comunidade sobre a importância desses valores. Spolsky (2009) ainda destaca que "O status de uma variante ou variedade deriva de quantas pessoas a usam e a importância de seus usuários, e os benefícios econômicos e sociais que um falante pode esperar usando-a." ${ }_{12}$ (SPOLSKY, 2009, p. 04). Uma ilustração é a visão do inglês, no Brasil, como língua associada ao progresso e à globalização, relacionada à ideia de que essa língua "abre portas no mundo".

Já a terceira dimensão é denominada de "planejamento", mas Spolsky $(2009,2012)$ prefere chamá-la de "gestão" e é definida como todos os esforços realizados por alguém, por um grupo, por um governo, ou por quem se julgue na autoridade de modificar as práticas ou as crenças dos participantes de um dado domínio social (família, escola, igreja etc.). Um exemplo são as ações criadas pelo programa Idiomas sem Fronteiras que objetivam melhorar a proficiência dos brasileiros na língua inglesa através, por exemplo, da criação do projeto My English Online.

Estas três dimensões influenciam as escolhas linguísticas de dada comunidade. Segundo o autor:

A teoria pressupõe que cada um destes três componentes constitui forças que ajudam na escolha linguística. As práticas fornecem os modelos linguísticos que ajudam a explicar a aprendizagem de línguas e assim estabelecer as condições necessárias para a escolha da língua - o comportamento da língua é determinado pela proficiência; as crenças explicam os valores que ajudam na escolha individual; e a gestão pode influenciar os falantes a modificar sua prática ou crença. ${ }^{13}$ (SPOLSKY, 2009, p.05-06)

Outra concepção ampliada de política linguística é a proveniente de Johnson (2013). Para o autor, a Política Linguística é um processo, em que vários agentes estão inseridos em "camadas" que envolvem

noticias-sobre-o-tema/>. Acesso em 21 de dezembro de 2018.

${ }^{12}$ No original: "The status of a variant or variety derives from how many people use it and the importance of the users, and the social and economic benefits a speaker can expect by using it"). (SPOLSKY, 2009, p. 04)

${ }^{13}$ No original: "The theory assumes that each of these three componentes contitutes forces which help account for language choice. The language practices provide the models of language that help explain language learning and so establish the necessary conditions for language choice - language behaviour is determined by proficiency; the beliefs explain the values that help account for individual choice; and the management may influence speakers to modify their practice or belief". (SPOLSKY, 2009, p.05-06). 
etapas de criação (como e por que uma política linguística foi criada), de interpretação (como uma política linguística pode ser interpretada pelos diferentes agentes) e de apropriação (como uma política linguística é colocada em prática). Ou seja, uma política linguística não é criada e implementada de forma direta, mas, envolve um contexto sociopolítico e depende da aceitação, modificação e/ou rejeição dos envolvidos em dado contexto.

Se considerarmos a esfera educacional, Johnson (2013) compreende que uma política linguística envolve desde o seu processo de criação (e.g.: instância governamental), passando por processos de interpretação e apropriação por outros agentes (secretários estaduais, dirigentes locais) que atuam como árbitros interferindo no processo de como uma política linguística educacional chegará ao espaço da sala de aula. A atuação dos árbitros pode ser ilustrada como na figura 2.

Figura 2 - Interferência dos árbitros na instância de Políticas Linguísticas

\section{Árbitro de Política Linguística 1}

\section{Política Linguística $\mathrm{X}$}

\section{Árbitro de Política Linguística 2}

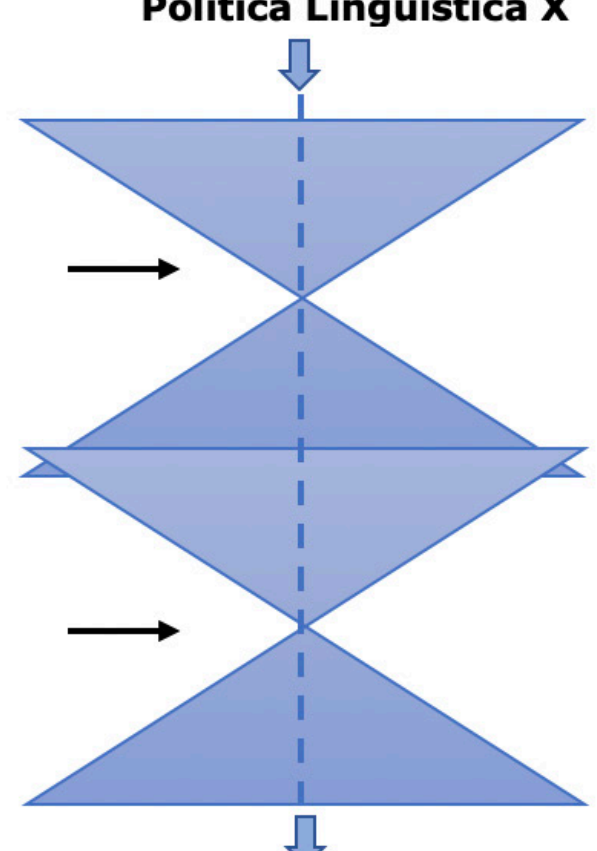

Instância da Política Linguística X

Fonte: Johnson (2013, p. 101).

Como é possível observar, essa concepção amplia ainda mais o que pode ser considerado política linguística, não a restringindo a uma ideia de produto e destacando os diversos atores sociais que estão envolvidos com dada política.

Após a descrição dessas concepções, na seção a seguir, apresentamos o percurso metodológico percorrido com o fito de 
v. 9 (3)

$382-402$

set-dez 2019

responder a seguinte pergunta: o campo de PPL está presente no currículo dos cursos de licenciatura de Letras dos institutos federais e das universidades públicas no Brasil e, se estiver, como se caracteriza essa presença?

\section{O processo de coleta e análise dos dados}

Para este trabalho, contemplamos todas as instituições de ensino superior que ofertassem o curso de Letras, através de uma base de dados (e-MEC) ${ }^{14}$ disponibilizada pelo Ministério da Educação (MEC). De acordo com a consulta realizada, os dados retornaram o número de 40 Institutos Federais de Educação Tecnológica, 63 Universidades Federais e 40 Universidades Estaduais, totalizando um total de 143 Instituições de Ensino Superior públicas. Na sequência, pesquisamos os sites de cada instituição com o intuito de observar se a instituição oferecia o curso de Licenciatura em Letras; se existisse o curso de Letras, recolhíamos os Projetos Político Pedagógicos e procurávamos disciplinas de Política Linguística e coletávamos a ementa. Durante este levantamento, identificamos também a presença de outros componentes curriculares com nomenclatura distinta da que estávamos procurando, mas com ementa que continha o sintagma "política linguística" ou sintagma similar, o que nos levou a ampliar o leque das disciplinas selecionadas. Apenas em uma ementa havia o sintagma "influência política", no entanto, parte de seu enunciado se relacionava ao conteúdo da área de PPL, o que justificou a inclusão desse componente curricular.

Considerando esses recortes, delimitamos a nossa pesquisa para 30 instituições (01 Instituto Federal, 08 Estaduais e 21 Federais). A figura 3 ilustra as Regiões em que as instituições estão localizadas no país.

${ }_{14}$ Disponível em: <http://emec.mec.gov.br/>. Acesso em: 26 de dezembro de 2017. 
Figura 03 - Estados que concentram instituições com licenciaturas em Letras que têm Política Linguística no currículo.

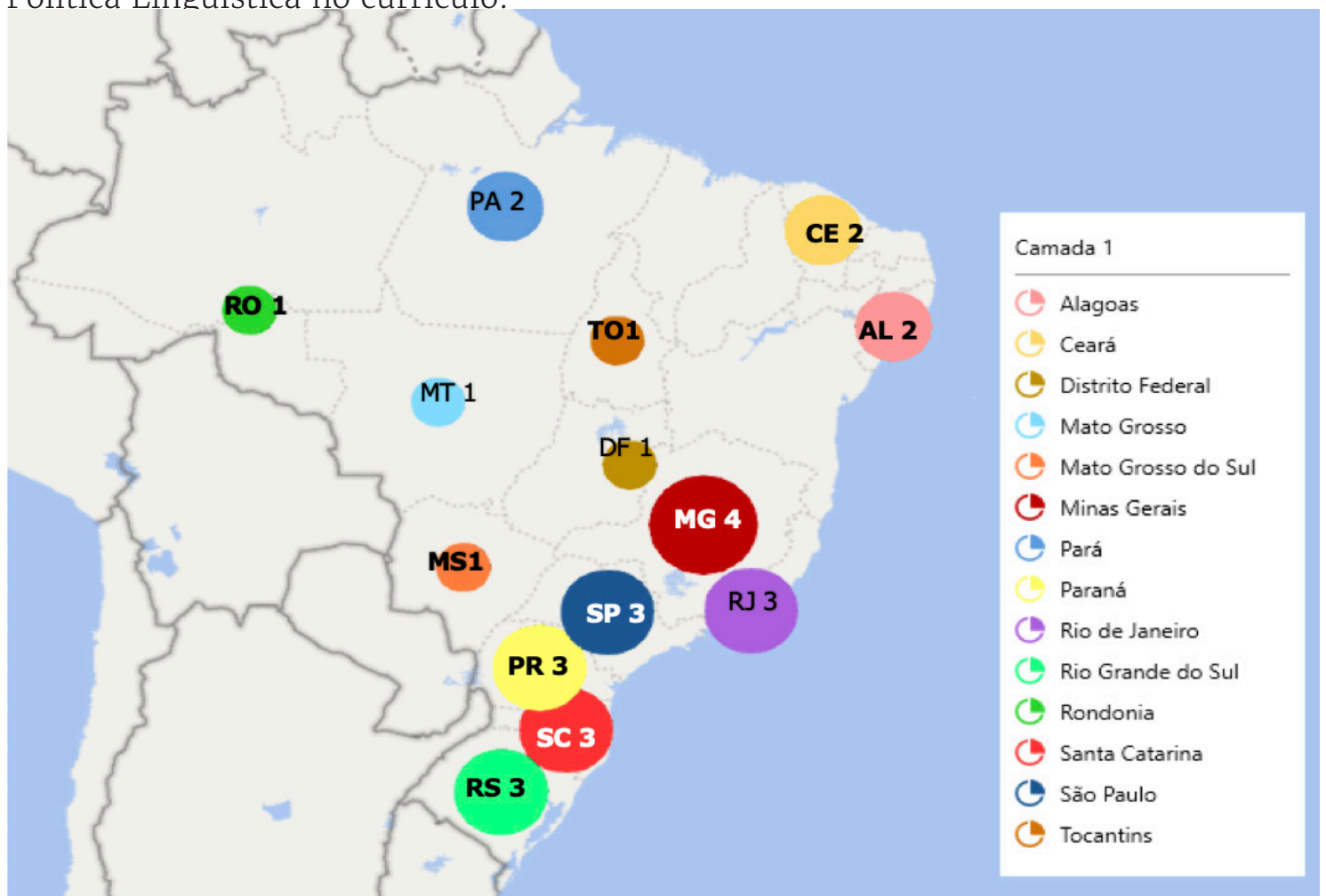

Fonte: Elaboração a partir dos dados coletados e do Bing/Microsoft.

Dentre as 30 instituições delimitadas para a pesquisa, selecionamos 34 Projetos Político Pedagógicos e 41 ementas de componentes curriculares. Algumas instituições possuem mais de um projeto (relacionados a habilitações distintas), e estes, por sua vez, podem apresentar uma ou mais de uma disciplina de Política Linguística ou outro (s) componente (s) curricular (es) com conteúdo da área. Por esta razão, não existe um número igual de instituições, projetos e componentes curriculares.

Os projetos analisados apresentaram como característica um recorte temporal de uma década (2006-2016) e cerca de 68\% dos projetos foram elaborados/reformulados nos últimos 04 anos (2012-2016). Já as habilitações, geralmente, são em Língua Portuguesa, dupla habilitação, considerando o ensino de Língua Portuguesa e outra língua, na maioria dos casos, Inglês ou Espanhol. Na pesquisa, também identificamos outras habilitações como, por exemplo, Língua Brasileira de Sinais, Ensino de Português como Segunda Língua ou como Língua Estrangeira e o curso de Licenciatura Intercultural Indígena que capacita professores para diversificadas áreas, dentre elas, a área de Língua Portuguesa e a respectiva língua indígena da comunidade na qual o futuro docente irá exercer a sua profissão. 
v. 9 (3)

$382-402$

set-dez

2019

Para a análise das ementas, categorizamos os conteúdos recorrentes de Política Linguística e buscamos relacionar esses achados com o que é preconizado nas Diretrizes Nacionais para os Cursos de Letras, com o tipo de curso ofertado e o contexto em que este está inserido e com a literatura da área de PPL.

\section{O espaço da PPL nas licenciaturas em Letras}

Dentre as 41 ementas, 13 eram disciplinas de Política Linguística $^{15}$ e 28 disciplinas continham o conteúdo de Política Linguística. Essas ementas eram provenientes de diferentes disciplinas como Linguística Aplicada (06), Sociolinguística (05) e outras (17), como por exemplo: "Línguas Indígenas na Amazônia" (Licenciatura Intercultural Indígena - UEPA), "Língua Espanhola 5" (Língua Espanhola - UFAL) ${ }^{16}$. O fato de esse conteúdo estar presente em disciplinas como Linguística Aplicada e Sociolinguística já era esperado, haja vista a Política Linguística, no seu início, ter sido considerada uma "sociolinguística aplicada" (CALVET, 2007, p.13) e estar sempre presente em compêndios de Linguística Aplicada (MENEZES; SILVA; GOMES, 2009).

Nos 28 componentes curriculares, categorizamos quatro formas distintas da presença do conteúdo da área de Política Linguística. A primeira: de forma indefinida, quando havia apenas a nomeação "Políticas linguísticas" ou "Política do Idioma" ou nomeação similar e não era possível definir que conteúdo seria explorado. Uma ilustração é a ementa da disciplina de "Organização e Gestão de Ambientes de Aprendizagem em Língua Portuguesa e Literatura Brasileira II", transcrita a seguir.

\footnotetext{
${ }_{15}$ Os componentes curriculares de Política Linguística apresentaram diferentes denominações como: "Política Linguística e Ensino de Língua", "Política Linguística", "Políticas Linguísticas", "Política do Idioma", Tópicos em Política Linguística" e "Tópicos de Política Linguística", "Política Linguística no Brasil", "Seminário Temático: Política Linguística no Brasil" e "Situação Linguística e Política Linguística entre os Guarani e Kaiowá".

${ }^{16}$ Afora as 2 disciplinas acima mencionadas, identificamos o conteúdo de Política Linguística nos seguintes componentes curriculares: "Organização e Gestão de Ambientes de Aprendizagem em Língua Portuguesa e Literatura Brasileira II", "Bilinguismo e Multilinguismo/Plurilinguismo", "Língua Brasileira de Sinais", "Variação Linguística e Ensino", "Dialetologia e Ensino de Língua Espanhola", "Educação Bilíngue", "Língua Portuguesa VII", "Fundamentos Linguísticos", "Povos Indígenas e Projetos Sociais II", "Língua Portuguesa VIII", "Planejamento e Orientações de Práticas de Ensino de Língua Inglesa I", "Planejamento e Orientação de Práticas de Ensino de Língua Espanhola I", "Tópicos sobre Variedade de Língua Espanhola", "Filologia Política" e "Ensino Bilíngue".
} 
Práticas escolares de ensino da língua portuguesa e literatura. Ensino de leitura e ensino de literatura. Políticas linguísticas. A questão curricular no ensino de língua portuguesa e literatura. Análise do uso do livro didático e instrumentos linguísticos. Produção de material didático. Avaliação do ensino aprendizagem em LPL. (Língua Portuguesa - IFFLUMINENSE) (Grifos nossos)

A segunda: de forma definida, quando havia a indicação de políticas linguísticas para dado contexto ou para uma língua específica. Exemplos são a ementa da disciplina "Bilinguismo e Multilinguismo/Plurilinguismo" na qual temos a presença do enunciado "Política linguística na América Latina" e a ementa da disciplina de "Sociolinguística" na qual identificamos o enunciado "Políticas Linguísticas sobre a Libras". Ambas estão descritas a seguir.

Definições e abordagens teóricas sobre monolinguismo, bilinguismo e multilinguismo/plurilinguismo. Bilinguismo e bilinguidade. Escolha linguística e discurso bilíngue: code-switching e code-mixing; Conscientização, manutenção e substituição linguísticas. Plurilinguismo e contatos linguísticos: contatos de imigração, contatos de fronteira, comunidades quilombola, comunidades indígenas, LIBRAS. Dinâmicas de transferência linguística nos diversos níveis, fonético-fonológico, morfossintático e léxico-semântico. Política linguística na América Latina. (Língua Espanhola e Língua Portuguesa como Línguas Estrangeiras - UNILA). (Grifos nossos)

Relações entre língua e a sociedade. Variação linguística no tempo e no espaço. Famílias linguísticas. Língua e dialeto. Comunidades de fala. Línguas em contato. Línguas emergenciais. Crioulização. Mudança linguística. Registro e diglossia. Os usos sociais da variação. Estudos Sociolinguísticos da Libras. Políticas Linguísticas sobre a Libras. Atividades de prática como componente curricular. (Língua Brasileira de Sinais - UFC) (Grifos nossos)

Acreditamos que a delimitação da política linguística a ser trabalhada na disciplina:

i) ou está intimamente ligada ao tipo de licenciatura. Ou seja, no curso de Língua Brasileira de Sinais da UFC os estudantes irão estudar as políticas linguísticas sobre essa língua;

ii) ou está ligada a um contexto sociolinguístico no qual o futuro professor irá atuar. Isto é, a UNILA, localizada em 
v. 9 (3)

$382-402$

set-dez

2019

Foz do Iguaçu, região que faz fronteira com o Paraguai e a Argentina, é o espaço no qual há contatos linguísticos entre falantes das principais línguas - o português e o espanhol e no qual os futuros docentes irão atuar. Afora essa questão, supomos, ainda, que a presença do conteúdo "Política linguística na América Latina" pode estar ligada a uma política de integração dessa região na qual a UNILA tem um papel principal e no qual o uso do português e do espanhol em seu espaço acadêmico são representativos dessa política.

A terceira: de forma definida, quando havia a indicação sobre o estudo de políticas de ensino de línguas específicas. Uma ilustração é a disciplina de "Planejamento e Orientação de Práticas de Ensino de Língua Espanhola I", transcrita a seguir.

A formação de professores de língua espanhola. História do espanhol e história do ensino do espanhol no Brasil. Legislação vigente acerca do ensino de língua estrangeira no país, especialmente a língua espanhola. Políticas públicas e linguísticas para o ensino de espanhol. (Língua Portuguesa/Língua Espanhola -UFTM) (Grifos nossos)

No exemplo destacado, fica clara a necessidade de o futuro professor de línguas conhecer as políticas linguísticas para o ensino da (s) língua (s) a (s) qual (ais) irá lecionar. Sobre esse conhecimento, Rajagoplan (2014, p. 73) destaca que

Os professores de língua nos mais variados níveis do sistema educacional de uma nação precisam ficar atentos a questões que dizem respeito à política linguística em vigor para não estarem em desacordo com as linhas gerais de orientação sinalizada nos estatutos e nas diretrizes formuladas. Qualquer desencontro dessa natureza contribui para fragilizar os esforços empenhados ou até mesmo gerar resultados contraproducentes.

Concordamos com o autor sobre a importância desse conhecimento, mas consideramos que este deve ir além da questão de o professor estar em consonância com as políticas linguísticas oficiais. Isso porque em sua sala de aula o professor é um agente de políticas linguísticas, podendo seguir, negociar e até rejeitar (de forma inconsciente) as orientações oficiais (MENKEN; GARCÍA, 2010). Foi o que concluiu Andrade (2016) ao investigar como os professores de língua portuguesa do Ensino Médio interpretavam e se apropriavam das orientações oficiais em relação ao eixo de análise linguística. 
A quarta: de forma definida, quando havia relação entre políticas linguísticas e suas implicações. Como exemplos temos a ementa da disciplina de "Tópicos sobre Variedade de Língua Espanhola" e de "Filologia Política", ambas descritas a seguir.

Análise da heterogeneidade do espanhol e de suas variedades. Estudo do contato do espanhol com o português brasileiro e outras línguas. Questões da política da língua espanhola e o ensino das suas variedades. (Língua Portuguesa/Língua Espanhola, UNIFESP). (Grifos nossos)

Disciplina - Filologia Política: Desenvolver perspectivas (inclusive dotadas de considerações interdisciplinares para pesquisa aplicada) que permitam visibilizar a construção de uma política de língua voltada ao ensino, no Brasil e no estrangeiro, como idioma de cultura, de literatura e de comércio, sem perder de vista as suas particularidades técnicas, situando num contexto universalista as transformações sociopolíticas das comunidades falantes com as suas reivindicações histórico-linguísticas, de indígenas, quilombolas, afrodescendentes ou de imigrantes, de toda ordem. (Língua Portuguesa, UNIR). (Grifos nossos)

Como é possível observar nos enunciados destacados, há na ementa de "Tópicos sobre Variedade de Língua Espanhola" uma relação explícita entre o estudo das políticas linguísticas e o tipo de ensino de variedade de língua a ser explorado em sala de aula e na ementa de "Filologia Política" uma descrição do futuro professor de línguas como um sujeito ativo. No primeiro caso, as discussões sobre as políticas da língua espanhola poderão permitir que este professor reflita sobre que variedade (s) de espanhol deve apresentar aos estudantes. A questão da "consciência" da diversidade linguística pelos formandos em Letras é considerada nas Diretrizes Curriculares para os Cursos de Letras como um elemento caracterizador deste perfil, conforme destacamos a seguir.

Independentemente da modalidade escolhida, o profissional em Letras deve ter domínio do uso da língua ou das línguas que sejam objeto de seus estudos, em termos de sua estrutura, funcionamento e manifestações culturais, além de ter consciência das variedades linguísticas e culturais. (BRASIL, 2001, p. 30) (Grifos nossos)

No excerto destacado, não basta o profissional de Letras ter o "domínio do uso da língua ou das línguas" que irá ensinar, ele precisa ter "consciência das variedades linguísticas e culturais", característica fundamental deste perfil, haja vista o uso do operador argumentativo "além de" apresentar um argumento mais importante (KOCH, 2000). 
v. 9 (3)

$382-402$

set-dez 2019

Considerando a disciplina de "Tópicos sobre Variedade de Língua Espanhola" que pretende formar professores de português e de espanhol, a preocupação com que variedade ensinar também está presente nas Orientações Curriculares para o Ensino Médio de Língua Espanhola. No documento, o docente é apresentado como um "articulador de muitas vozes" na medida em que mesmo dominando uma variedade específica deveria mostrar aos alunos um modo de "criar oportunidades de aproximação a elas, derrubando estereótipos e preconceitos" (BRASIL, 2006, p. 186).

No outro exemplo, a disciplina de "Filologia Política" tem como objetivo levar o estudante a "construir" uma política de língua para o ensino de língua portuguesa que esteja em consonância com suas diferentes dimensões - língua de cultura, da literatura, do comércio - e com o contexto em que for ensinada. Em nossa interpretação, o futuro professor é apresentado como um agente de políticas linguísticas e nesse sentido, ele se constitui no "epicentro desse processo dinâmico, atuando com a sua agência para modificar as várias políticas linguísticas educacionais que devem ser traduzidas em práticas"17 (MENKEN; GARCÍA, 2010, p.02).

Já em relação às disciplinas de Política Linguística, encontramos alguns resultados semelhantes e outros diferentes. A primeira categoria que selecionamos foi a relação entre a área de Política Linguística e o ensino de língua como está exibido na ementa da disciplina de "Política Linguística e Ensino de Língua" a seguir: "Principais aportes teóricos ligados ao campo das Políticas Linguísticas. Conexões com o ensino de língua. " (Grifos nossos). Embora não tenhamos como identificar que conteúdos são esses, é fundamental destacarmos a ligação destes com o ensino de línguas, o que já materializa uma contribuição explícita da área de PPL na formação de professores de línguas, a exemplo da obra "Política Linguística e Ensino de Língua" (CORREA, 2014).

Na segunda categoria agrupamos os conteúdos referentes ao estudo sobre as políticas linguísticas de uma língua, ou as políticas de ensino de uma língua ou, ainda, as políticas linguísticas para um contexto específico, aspectos ilustrados na ementa da disciplina de "Política do Idioma", exibida abaixo.

${ }^{17}$ No original: "Educators are at the epicenter of this dynamic process, acting on their agency to change the various language education policies they must translate into practice." (MENKEN; GARCÍA, 2010, p. 02). 
Língua, poder e cidadania Estudo da situação da língua portuguesa na Europa, na América do Sul, na África e no Timor Leste. As políticas de difusão da língua portuguesa na União Europeia e no Mercosul. O ensino da língua portuguesa nos PALOP. O estatuto do Português do Brasil nas políticas de difusão do idioma. Leis de preservação do idioma nacional e resultados no ensino. Políticas nacionais para o ensino do português como língua materna e como segunda língua. (Português do Brasil como Segunda Língua - UNB). (Grifos nossos)

Nesta disciplina, são enfocadas as políticas linguísticas educacionais para o ensino do português como L1 e L2 e as políticas de difusão dessa língua em contextos como a União Europeia e Mercosul, conteúdos que são fundamentais em um curso de Português do Brasil como Segunda Língua. Destacamos, ainda, que enunciados sobre as políticas de difusão do português como uma língua internacional também estão presentes em outras ementas. Segundo Afonso (2017), abordar as políticas de difusão da língua portuguesa é um conteúdo praticamente indispensável haja vista o caráter de algumas universidades (a UNILAB e a UNILA $^{18}$ têm como objetivos a integração regional); a proximidade com regiões de fronteira e o tipo de licenciatura oferecida.

Nesta categoria, também destacamos o conteúdo sobre as políticas linguísticas no Brasil que está presente em várias disciplinas e está ilustrada a seguir na ementa da disciplina "Política Linguística no Brasil": "As políticas linguísticas no Brasil. Da política linguística de Marquês de Pombal até os dias atuais. A Declaração Universal dos Direitos Humanos e a política linguística no Brasil e no Mundo. " (Língua Portuguesa/Língua Espanhola - UFFS) (Grifos nossos).

A terceira categoria diz respeito ao estudo das políticas linguísticas e suas implicações. Os componentes curriculares de "Políticas Linguísticas", ilustram essa categoria.

Conceitos norteadores de política (s) linguística (s). Modelos e exemplos de políticas linguísticas. Impactos das políticas linguísticas nas práticas sociais de diferentes comunidades, com enfase em comunidades bilíngues, multilíngues e minoritárias. (Línguas Adicionais: Inglês e Espanhol - UNIPAMPA). (Grifos nossos)

Gestos de intervenção sobre as línguas e seus efeitos na constituição histórica dos grupos sociais. Línguas e suas divisões: oficiais, nacionais, transnacionais, francas, maternas, estrangeiras,

\footnotetext{
${ }^{18}$ A UNILA e a UNILAB foram universidades criadas na época do governo do ExPresidente Luiz Inácio Lula da Silva com o objetivo de estabelecer a integração regional, respectivamente, entre o Brasil e os países latino-americanos e entre o Brasil e os países da Comunidade de Língua Portuguesa (CPLP).
} 
v. 9 (3)

$382-402$

set-dez

2019 entre outras. Línguas minoritárias e línguas de Estado. Políticas de ensino de línguas e planificação. Relações entre línguas e relações entre Estados nacionais. Organismos supranacionais e políticas linguísticas. Documentação de línguas. Português globalizado. (Português como Segunda Língua/Língua Estrangeira - UNICAMP). (Grifos nossos)

Os enunciados negritados nestas ementas deixam evidente a necessidade de reflexão sobre os efeitos das políticas linguísticas, o que vai além do conhecimento sobre as políticas de uma língua, de ensino de uma língua ou para um contexto específico. Compreendemos que esse conteúdo está em consonância com o texto das Diretrizes Curriculares para os Cursos de Letras que destaca que o formando deve ter a competência e habilidade de ter "percepção de diferentes contextos interculturais" (BRASIL, 2001, p. 30). A nosso ver, essa percepção será possível a partir da reflexão dos "Impactos das políticas linguísticas nas práticas sociais de diferentes comunidades, com ênfase em comunidades bilíngues, multilíngues e minoritárias".

As implicações das políticas linguísticas também estão presentes no enunciado "Gestos de intervenção sobre as línguas e seus efeitos na constituição histórica dos grupos sociais", o que poderá permitir ao formando refletir sobre algumas ideologias linguísticas vigentes no Brasil como é o caso de que 'brasileiro é monolíngue' que, por sua vez, contrasta com os dados sobre a quantidade de línguas indígenas que ainda são faladas por diferentes comunidades em nosso país (OLIVEIRA, 2009).

Já a quarta categoria refere-se a noções teóricas sobre a área de Política Linguística que está expressa, por exemplo, no enunciado "Conceitos norteadores de política (s) linguística (s)" da ementa da disciplina de "Política Linguística" exibida acima.

Em suma, consideramos que a identificação de disciplinas de Política Linguística e de conteúdos da área de PPL em outros componentes curriculares é uma forma de materializar a orientação das Diretrizes Curriculares para os Cursos de Letras que estabelecem como competência e habilidade do formando a "reflexão analítica e crítica sobre a linguagem como fenômeno psicológico, educacional, social, histórico, cultural, político e ideológico" (BRASIL, 2001, p. 30) (Grifos nossos). Nesse sentido, acreditamos que a área pode propiciar aos futuros professores de línguas o (re) conhecimento sobre a dimensão política (e constitutiva) da língua. E esse (re) conhecimento pode ter implicações para os futuros docentes, tais como: 
i) a percepção de que a prática pedagógica pode influenciar o comportamento linguístico dos alunos no que se refere à aquisição, reaquisição ou manutenção de uma língua (COOPER, 1989), bem como à valoração que estes têm em relação às línguas e as variedades linguísticas (SPOLSKY, 2004, 2009, 2012);

ii) a percepção do professor como um sujeito ativo frente às orientações curriculares oficiais, haja vista as políticas oficiais envolverem sempre um processo de interpretação e de apropriação e não simplesmente de implementação (JOHNSON, 2013);

iii) o (re) conhecimento de que há políticas linguísticas explícitas e implícitas na escola (e.g.: carga horária da disciplina, parâmetros selecionados na correção da produção textual dos alunos) (SCHIFFMAN, 1996, 2006);

iv) a reflexão sobre suas próprias crenças em relação às línguas e variedades e como elas podem influenciar nas suas escolhas pedagógicas do professor (e.g: seleção de um livro didático) (SPOLSKY, 2004, 2009, 2012).

\section{Considerações finais}

Este artigo pretendeu responder à seguinte pergunta: a área de PPL está presente no currículo dos cursos de licenciatura de Letras no Brasil e, se estiver, como se caracteriza essa presença? O levantamento dos Projetos Político Pedagógicos nos permite afirmar que, embora a PPL seja um campo de conhecimento recente, nascido após a Segunda Guerra Mundial (RICENTO, 2000), já faz parte do currículo de algumas licenciaturas em Letras em todas as Regiões do Brasil como disciplina e como conteúdo relativo à área em diferentes componentes curriculares. Verificamos que nas ementas de Política Linguística e de outras disciplinas estão presentes os seguintes conteúdos:

Quadro 01 - Conteúdos da área de PPL nas licenciaturas em Letras.

\begin{tabular}{|l|l|}
\hline Nas disciplinas de Política Linguística & Em outras disciplinas \\
\hline $\begin{array}{l}\text { Políticas linguísticas para uma língua } \\
\text { específica e/ou para um contexto } \\
\text { específico }\end{array}$ & $\begin{array}{l}\text { Políticas linguísticas para uma língua } \\
\text { específica e/ou para um contexto } \\
\text { específico }\end{array}$ \\
\hline Políticas de ensino de línguas específicas & Políticas de ensino de línguas específicas \\
\hline Políticas linguísticas e suas implicações & Políticas linguísticas e suas implicações \\
\hline
\end{tabular}


V. 9 (3)

$382-402$

set-dez

2019

\begin{tabular}{|l|l|}
\hline $\begin{array}{l}\text { A relação entre a área de PPL e o ensino } \\
\text { de língua }\end{array}$ & $\begin{array}{l}\text { De forma indefinida, apenas com a } \\
\text { denominação "política linguística" ou } \\
\text { sintagma similar }\end{array}$ \\
\hline Noções gerais de PPL & \\
\hline
\end{tabular}

Fonte: Elaboração própria

Os resultados indicam que o conhecimento da dimensão política da língua é uma competência necessária na formação de professores, provendo a este uma perspectiva mais ampla de língua, o que pode torná-lo mais preparado para lidar com os diferentes desafios de ser professor em um mundo globalizado, em contexto de falantes de línguas minorizadas, em contextos sociolinguísticos complexos como as regiões de fronteiras, dentre outros. Os resultados também materializam o texto das Diretrizes Curriculares para os Cursos de Letras que orientam a exploração dessa dimensão da língua, o que já é esperado tendo em vista que este é o documento que deve nortear os cursos de Letras.

Como foi possível observar, o conhecimento da área de PPL pode ter diferentes implicações para as práticas de ensino, que, por sua vez, podem reverberar nas mudanças dos comportamentos linguísticos e das crenças dos estudantes e dos professores sobre as línguas e a importância dessas valorações. É ter essa consciência que poderá tornar o futuro docente ciente do seu papel como um principal árbitro no processo de política linguística.

\section{Referências}

AFONSO, L. A. A Área de Política Linguística nas Licenciaturas em Letras no Brasil. 2017. 108 f. Dissertação (Mestrado em Linguística) Universidade Federal da Paraíba, João Pessoa, 2017.

ANDRADE, R. C, O. de. Políticas linguísticas educacionais em Pernambuco: um estudo do eixo de análise linguística. 2016. 196 f. Dissertação (Mestrado em Linguística), Universidade Federal da Paraíba. João Pessoa, 2016.

ARIAS, M. B.; WILEY, T. G. Language policy and teacher preparation: the implications of a restrictive language policy on teacher preparation. De Gruyter Mounton, v. 4, n. 1, p. 83-104, 2013.

BRASIL. Parecer CNE/CES 492/2001. Disponível em: <http://portal.mec.gov. br/cne/arquivos/pdf/CES0492.pdf>. Acesso em: 06 set. 2017.

BRASIL. Orientações curriculares para o ensino médio: linguagens, Códigos e suas Tecnologias. Brasília: Ministério da Educação, Secretaria de Educação Básica, 2006. v. 1. 
CALVET, L.-J. As políticas linguísticas. São Paulo: Parábola Editorial/IPOL, 2007.

COOPER, R. L. Language planning and social change. Cambridge: Cambridge University Press, 1989.

CORREA, D. A. (Org.). Política linguística e ensino de língua. Campinas/S.P.: Pontes, 2014.

FRAGA, L. Políticas linguísticas na formação do licenciado em Letras: uma discussão introdutória. In: CORREA, D. A. (Org.). Política linguística e ensino de língua. Campinas/São Paulo: Pontes Editores, 2014. p. 45-59.

HAUGEN, E. Planning for a standard language in modern Norway. Anthropological Linguistics, p. 8-21, 1959.

JOHNSON, D. C. Language policy. New York: Palgrave Macmilliam, 2013.

KOCH, I. G. V. Argumentação e linguagem. 6. ed. São Paulo: Cortez, 2000.

MENEZES, V.; SILVA, M. M.; GOMES, I. F. Sessenta anos de Linguística Aplicada: de onde viemos e para onde vamos. In: PEREIRA, R. C.; ROCA, P. (Orgs.). Linguística Aplicada: um caminho com diferentes acessos. São Paulo: Contexto, 2009. p. 25-50.

MENKEN, K.; GARCÍA, O. Introduction. In: MENKEN, K.; GARCÍA, O. (Orgs.). Negotiating language policies in schools. New York: Routledge, 2010. p. 0110 .

OLIVEIRA, G. M. Brasileiro fala português: monolinguismo e preconceito linguístico. In: MOURA, H. M. M.; SILVA, F. L. (Orgs.). 0 direito à fala: a questão do preconceito linguístico. Florianópolis: Insular, 2000. p. 83-92.

RAJAGOPALAN, K. O professor de línguas e a suma importância do seu entrosamento na política linguística do seu país. In: CORREA, D. A. (Org.). Política linguística e ensino de língua. Campinas/São Paulo: Pontes Editores, 2014. p. 73-82.

RICENTO, T. Historical and theoretical perspectives in language policy and planning. Journal of Sociolinguistics. V. 4, n. 2, p. 196-213, 2000.

SCHIFFMAN, H. F. Linguistic culture and language policy. London/New York: Routledge, 1996.

SCHIFFMAN, H. F. Language policy and linguistic culture. In: RICENTO, T. (Org.) A introduction to language policy: theory and method. Blackwel: London, 2006.

SILVA, E. R. da. A pesquisa em Política Linguística: histórico, desenvolvimento e pressupostos epistemológicos. Trabalhos em Linguística Aplicada. Campinas, n. 52, v. 2, p. 289-320, jul./dez. 2013.

SOUSA, S.C.T.; ROCA, M. del P. Introdução para uma compreensão ampliada de Política Linguística. In: Políticas Linguísticas: declaradas, praticadas e percebidas. João Pessoa: Ideia, 2015. p. 07-32. 
v. 9 (3)

382-402

set-dez 2019

SPOLSKY, B. Language policy: key topics in Sociolinguistics. Cambridge: Cambridge University Press, 2004.

SPOLSKY, B. Language Management. Cambridge: Cambridge University Press, 2009.

SPOLSKY, B. The Cambridge Handbook of Language Policy. Cambridge: Cambridge University Press, 2012.

THROOP, R. Teachers as language policy planners: incorporating language policy planning into teacher education and classroom practice. Working Papers in Educational Linguistics, v. 22, n. 2, p. 45-65, 2007. 